\title{
Lupus and pulmonary nodules consistent with bronchiolitis obliterans organizing pneumonia induced by carbamazepine in a man
}

\author{
Awatef Kelati, Salim Gallouj, Mariame Meziane, Fatima Zahra Mernissi
}

Department of Dermatology of the Hospital Hassan II, Faculty of Medicine, Fez, Morocco

Corresponding author: Dr. Awatef Kelati, E-mail: awatkelati@gmail.com

\begin{abstract}
Several drugs have been implicated in the induction of systemic lupus erythematosus (SLE), but there are only some observations of carbamazepine induced SLE since the first case described in 1966, this drug has also been implicated in the induction of other disorders and rarely pulmonary toxicity; but the occurrence of two rare side effects of this drug: the induced SLE and pulmonary nodules consistent with the bronchiolitis obliterans organizing pneumonia in same patient is really unusual and -to our knowledge- the second observation reported in the literature.
\end{abstract}

Key words: Carbamazepine; Lupus; Bronchiolitis obliterans organizing pneumonia

\section{INTRODUCTION}

Several drugs have been implicated in the induction of systemic lupus erythematosus (SLE), but there are only some observations of carbamazepine induced SLE since the first case described in 1966 [1], this Carbamazepine (CBZ) has been used as an anticonvulsant since 1962 and is a drug of choice for treatment of simple or complex partial seizures and generalized secondary seizures in both children and adults $[2,3]$ and which could be responsible for many side effects including sleep disorders, anorexia, nausea, vomiting, irritability, ataxia and diplopia, yet, CBZ pulmonary toxicity is rare, because only few case reports of interstitial pneumonitis, bronchospasm, pulmonary edema, pulmonary nodules and bronchiolitis obliterans organizing pneumonia (BOOP) have been reported [4-6].

Our case demonstrates two rare side effects of this drug: the induced SLE and pulmonary nodules consistent with the BOOP which is really unusual and -to our knowledge- the second observation [7] reported in the literature.

\section{CASE REPORT}

A 59 -years- old man followed since the age of 12 years for epilepsy and was under treatment by CBZ since one year.

He presented after 2 months of the use of CBZ, erythematous plaques like the butterfly wings on the face according to the patient tell and erythema on the back, the hands and feet with photosensitivity, inflammatory arthralgias and intermittent dry cough.

Clinical examination found bilateral malar erythematous plaques (Fig. 1) and erythematous plaques of the neckline, the back and the dorsal surface of the hands and purpuric plaques at the palmar surfaces of the hands and soles of the feet (Figs. 2 and 3) with a nibbled appearance on pulps of the fingers and erythematous alopecia patches of the scalp.

Initial Blood investigations revealed anemia (haemoglobin of $10.5 \mathrm{~g} / \mathrm{dl}$ ), thrombocytopenia (platelet count of $100000 / \mathrm{mm}^{3}$ ), leukopenia (white cell count of 1900/. $\mathrm{mm}^{3}$ ) and especially lymphopenia (lymphocytes

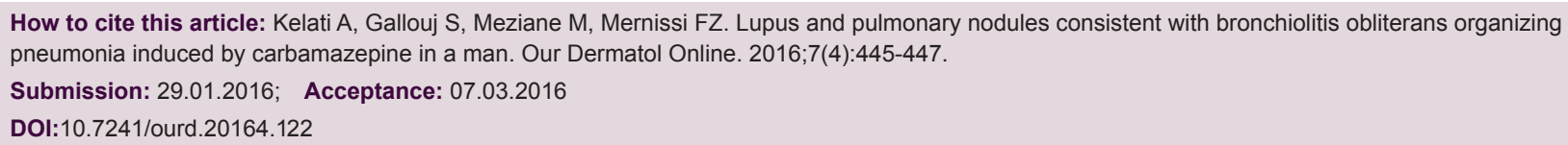




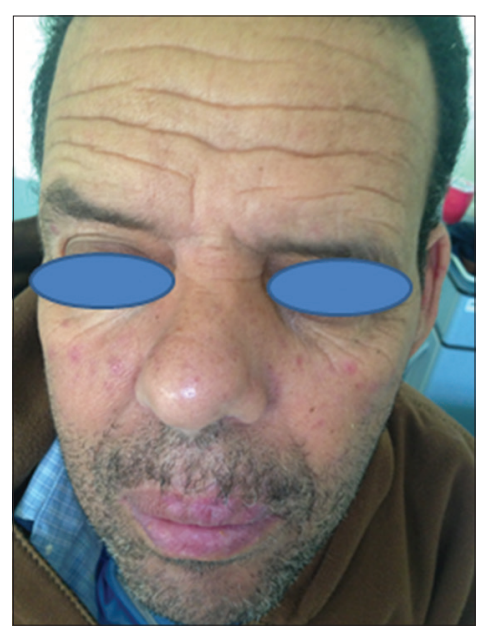

Figure 1: Clinical image showing bilateral malar erythematous plaques of lupus.

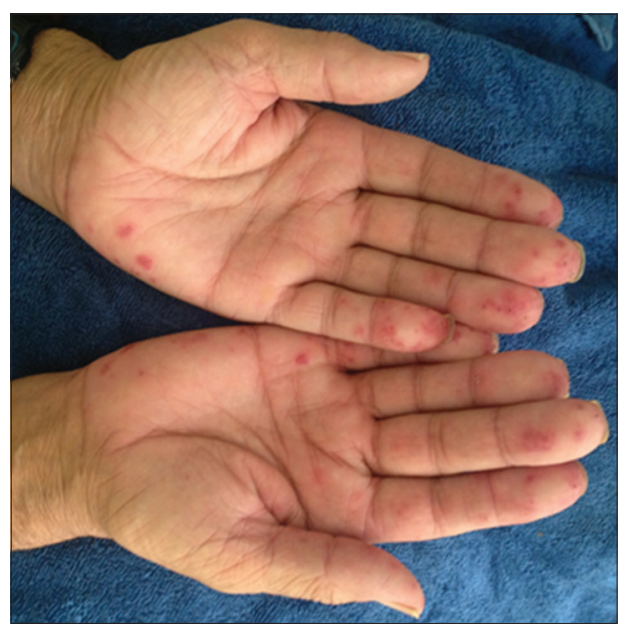

Figure 2: Clinical image showing erythematous purpuric plaques at the palmar surfaces of the hands.

count of 1000/ $\mathrm{mm}^{3}$ ) with a positive rate of antinuclear antibodies in a titer of 1/160, anti-dsDNA: $100 \mathrm{u} / \mathrm{ml}$ and positive rate of anti-histones without complement deficiency. The erythrocyte sedimentation rate and the levels of C-reactive protein were slightly increased (35 mg/L and $50 \mathrm{~mm} / \mathrm{h}$ ).

The skin biopsy confirmed the diagnosis of lupus. The chest radiography demonstrated bilateral interstitial infiltrates with multiple lung nodules (Fig. 4) more visible in the chest tomographic scan (Fig. 5), so a pulmonologist advice was asked and an infectious or occupational (silicone) origin were eliminated. The histological examination of this pulmonary infiltrate was not performed.

Ultimately, the diagnosis of CBZ induced lupus was retained based on clinical, biological and histological

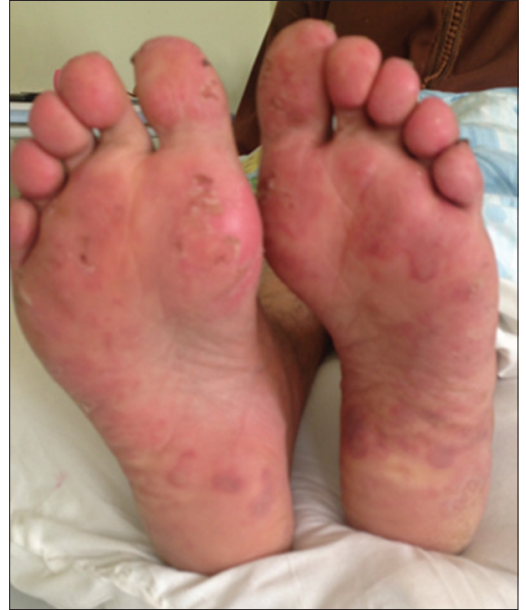

Figure 3: Clinical image showing erythematous purpuric plaques at the soles of the feet.

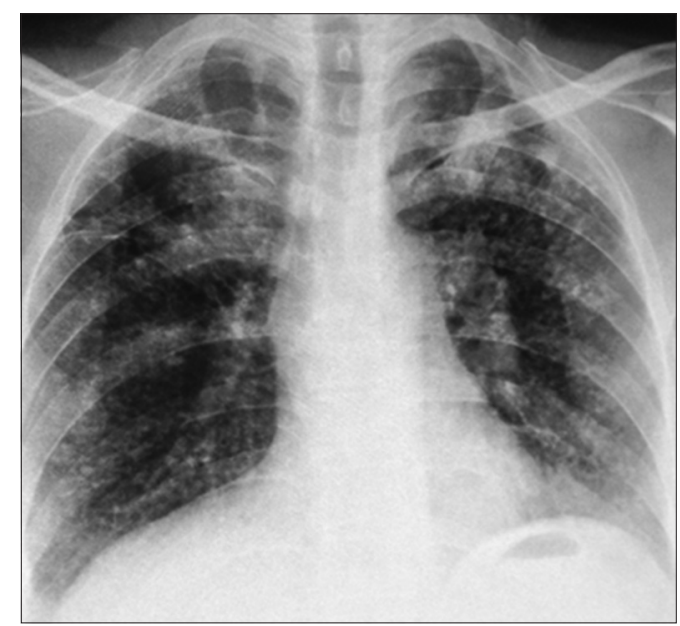

Figure 4: The chest radiography image demonstrating bilateral interstitial infiltrates with multiple lung nodules.

criteria and after the pharmacovigilance advice. In addition, the lung lesions were diagnosed as BOOP also induced by the CBZ.

Based on these facts, the CBZ was stopped and we prescribed a low dose of corticosteroids to our patient $(0.5 \mathrm{mg} / \mathrm{kg} / \mathrm{j})$ and Hydroxychloroquine with a good evolution.

\section{DISCUSSION}

The drug induced lupus has been known since more than 50 years. In 1945, this diagnosis was suggested by Hoffman [8] and has been described in 1952 with Hydralazine, since then, hundreds of publications have been devoted to this subject [9-11], including some cases of CBZ induced SLE since Simpson described the first case in 1966 [8,12-14]. 


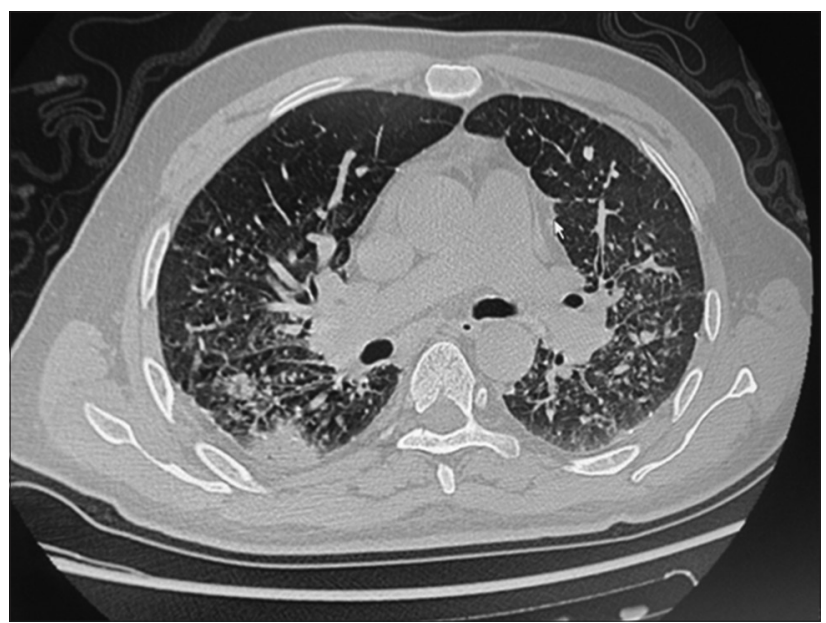

Figure 5: The chest tomographic scan image showing nodules of Bronchiolitis Obliterans Organizing Pneumonia.

On the other hand, BOOP is a nonspecific scarring process that occurs in response to injury of the bronchioles, it is characterized histologically by the presence of inflammatory fibrinous plugs obstructing the terminal and respiratory bronchioles (bronchiolitis obliterans) and extending into the alveolar ducts and adjacent alveoli (organizing pneumonia) [15]. It was first described in 1985 as an idiopathic entity and rarely a secondary process in several clinical settings, such as wegener granulomatosis, lymphoma or other neoplasms, bronchiectasis, acute respiratory infections, radiation treatment, or appear idiopathically [6]. BOOP has been also described in association with the use of some drugs like the acebutolol, amiodarone, cephalosporin, bleomycin, tryptophan, gold salts, barbiturates, sulfasalazine, o-penicillamine, [7] and in one case, it was described as a side effect of CBZ in a lupus patient, as the case of our patient which is the second observation reported.

Generally, both the induced lupus and the BOOP have usually a good outcome after the cessation of the drug [6], and corticosteroids improves the visceral involvement in the systemic lupus, which was the case of our patient.

\section{CONCLUSION}

The originality of our case is the rare induction of SLE and BOOP by Carbamazepine in a man, which represent another real warning regarding this drug use.

\section{Consent}

The examination of the patient was conducted according to the Declaration of Helsinki principles.

\section{REFERENCES}

1. Simpson JR. "Collagen disease" due to carbamazepine (Tegretol). BMJ. 1966;2:1434.

2. Goncalves D, Moura R, Ferraz C, Vitor AB, Vaz L. Carbamazepineinduced interstitial pneumonitis associated with panhypogammaglobulinemia. Respir Med Case Rep. 2012;5:6-8.

3. Loiseau P. Carbamazepine: clinical efficacy and use in epilepsy. Antiepileptic drugs. 5th ed. Philadelphia: Lippincott Williams \& Wilkins; 2002:262-72.

4. Archibald N, Yates B, Murphy D, Black F, Lordan J, Dark J, Corris PA. Carbamazepine-induced interstitial pneumonitis in a lung transplant patient. Respir Med. 2006;100:1660-2.

5. Banka R, Ward MJ. Bronchiolitis obliterans and organising pneumonia caused by carbamazepine and mimicking community acquired pneumonia. Postgrad Med J. 2002;78:621-2.

6. Tamada T, Nara M, Tomaki M, Ashino Y, Hattori T. Secondary bronchiolitis obliterans organising pneumonia in a patient with carbamazepine-induced hypogammaglobulinemia. Thorax. 2007;62:100.

7. Milesi-Lecat AM, Schmidt J, Aumaitre O, Kemeny JL, Moinard J, Piette JC. Lupus and pulmonary nodules consistent with bronchiolitis obliterans organizing pneumonia induced by carbamazepine. Mayo Clin Proc. 1997;72:1145-7.

8. Hoffman BJ. Sensitivity of sulfadiazine resembling acute disseminated lupus erythematosus. Arch Dermatol Syph. 1945;51:130-2.

9. Morrow JD, Schroeder HA, Perry HM. Studies on the control of hypertension by hyphex. II. Toxic reactions and side effects. Circulation. 1953;8:829-39.

10. Le Goff P, Saraux A. Les lupus induits. Rev Rhum [Ed Fr]. 1999;66:43-8.

11. Masson C, Couchouron T, Audran M. Lupus induits. Rev Rhumat. 2005;72:168-75.

12. Molina-Ruiz AM, Lasanta B, Barcia A, Pérez-Vega E, Requena L. Drug-induced systemic lupus erythematosus in a child after 3 years of treatment with carbamazepine. Australas J Dermatol. 2015 Sep 30.

13. Harnett DT, Chandra-Sekhar HB,Hamilton SF. Druginduced lupus erythematosus presenting with cardiac tamponade: a case report and literature review. Can J Cardiol. 2014;30:247.e11-2.

14. Pelizza L, De luca P, La Pesa M, Minervino A. Drug-induced systemic lupus erythematosus after 7 years of treatment with carbamazepine. Acta Biomed. 2006;77:17-9.

15. Gray R E. Bronchiolitis Obliterans Organizing Pneumonia. Arch Intern Med. 2001;161:158-64.

Copyright by Awatef Kelati, et al. This is an open access article distributed under the terms of the Creative Commons Attribution License, which permits unrestricted use, distribution, and reproduction in any medium, provided the original author and source are credited.

Source of Support: Nil, Conflict of Interest: None declared. 